\title{
Age at menarche and age at first sexual intercourse: a prospective cohort study
}

Jennifer L. Marino ${ }^{1}$, MPH, PhD, S. Rachel Skinner ${ }^{2}$, MBBS, PhD, FRACP, Dorota A. Doherty $^{3,4}$, PhD, Susan Rosenthal ${ }^{5}$, PhD, ABPP, Spring C. Cooper Robbins ${ }^{2}$, PhD, Jeffrey Cannon ${ }^{4}$ BSc, BBus, Martha Hickey ${ }^{1}$ MSc, MBChB, FRANZCOG, MD

Affiliations: ${ }^{1}$ Department of Obstetrics and Gynaecology, University of Melbourne, Melbourne, Australia and the Royal Women's Hospital, Parkville, Australia; ${ }^{2}$ Discipline of Paediatrics and Child Health, The University of Sydney, Children's Hospital Westmead, Sydney, Australia; ${ }^{3}$ School of Women's and Infants' Health, The University of Western Australia, Subiaco, Australia; ${ }^{4}$ Women and Infants Research Foundation, Perth, Australia; ${ }^{5}$ Department of Pediatrics, Columbia University Medical Center, and New York-Presbyterian Morgan Stanley Children's Hospital, New York, NY.

Address correspondence to: Jennifer L. Marino, jennifer.marino@unimelb.edu.au, Department of Obstetrics \& Gynaecology, Level 7, Royal Women's Hospital, 20 Flemington Road, Parkville, Victoria, 3052. Phone number: +61 0383453718

Short title: Age at menarche and age at first sexual intercourse

Abbreviations: AAM: age at menarche; CI: confidence interval; FSI: first sexual intercourse; HR: hazard ratio; IQR: interquartile range.

Key Words: Sexual Behavior, Reproductive Behavior, Puberty, Risk-taking Behavior

Funding Sources: The core management of the Western Australia Pregnancy Cohort (Raine) Study is funded by the Raine Medical Research Foundation, The University of Western Australia (UWA), the Telethon Institute for Child Health Research, the UWA Faculty of Medicine, Dentistry and Health Science, the Women and Infants Research Foundation and Curtin University. Antenatal data collection was funded by the Raine Medical Research Foundation. The 17-year follow-up was funded by National Health and Medical Research Council of Australia (NHMRC) Program Grant \#353514. The 20-year follow-up was funded by NHMRC Grants \#963209, \#211912, \#003209, \#634445, \#634457, \#634509, and \#1003424, the Canadian Institutes of Health Research (MOP-82893), and the Lions Eye Institute. No funding source was involved in any aspect of the study design, analysis of data or manuscript preparation.

Financial Disclosures: The authors have no financial relationships relevant to this article to disclose.

Conflict of Interest: The authors have no conflicts of interest relevant to this article to disclose.

What's Known on This Subject: Young age at first sexual intercourse (FSI) is related to risktaking behaviors and negative outcomes. Previous studies using cohort or cross-sectional design have concluded that younger age at menarche (AAM) is related to younger age at FSI.

What This Study Adds: This large birth cohort study is the first to address the temporal relationship between AAM and FSI. We found that younger AAM does not confer higher risk of early FSI, whether in terms of calendar age or time since menarche.

Word Count: 2925

Tables and Figures: Four tables, two figures 


\section{Contributors' Statement}

Jennifer L. Marino: Dr. Marino contributed to the conception and design of the study, contributed to the analysis and interpretation of data, drafted the manuscript jointly with Prof. Hickey, and approved the final manuscript as submitted.

S. Rachel Skinner: A/Prof. Skinner contributed to the conception and design of the study, contributed to the acquisition of the data, contributed to the interpretation of data, critically reviewed the manuscript and approved the final manuscript as submitted.

Dorota A. Doherty: Dr. Doherty contributed to the conception and design of the study, contributed to the acquisition of data, planned and coordinated data analysis, contributed to the interpretation of data, critically reviewed the manuscript and approved the final manuscript as submitted.

Susan Rosenthal: Prof. Rosenthal contributed to the interpretation of data, critically reviewed the manuscript and approved the final manuscript as submitted.

Spring Cooper Robbins: Dr. Cooper Robbins contributed to the acquisition of data, critically reviewed the manuscript and approved the final manuscript as submitted.

Jeffrey Cannon: Mr. Cannon analyzed the data, contributed to the interpretation of data, critically reviewed the manuscript and approved the final manuscript as submitted.

Martha Hickey: Prof. Hickey conceived and designed the study, contributed to the acquisition of the data, drafted the manuscript jointly with Dr. Marino, and approved the final manuscript as submitted. 


\begin{abstract}
Objective: Younger age at menarche (AAM) may put girls at risk for earlier first sexual intercourse (FSI). Young age at FSI may have wide-reaching negative outcomes. We describe the relationship between AAM and FSI in a large prospective birth cohort using longitudinal analyses.

Methods: AAM was collected from 554 girls from the WA (Raine) Pregnancy Cohort Study, prospectively from age 10 or retrospectively at age 14-16 years. Age at FSI was collected at ages 17 and 20. Cox regression models describe the likelihood of FSI by age and years since menarche for younger $(<12 y)$ and older $(\geq 14 y)$ AAM relative to average AAM $(12-13 y)$.

Results: Median AAM was 12.8 years. By age 16-17, 275 (49.6\%) and by age 20-21, 429 (77.4\%) girls reported FSI. Girls with younger AAM and girls with average AAM were equally likely to have FSI by age 16 (aHR $0.90,95 \%$ CI $0.60-1.35$ ). FSI by age 16 was less likely in girls with older AAM compared to those with average AAM (aHR 0.35, 95\% CI 0.17-0.72).

Girls with younger AAM had a longer median interval between menarche and FSI than girls with average AAM (5.0 years, IQR 4.4-8.5 years vs. 3.7 years, IQR 2.4-5.3 years). Those with younger AAM were less likely to report FSI than those with average AAM <4 years of menarche (0-2 years HR 0.04, 95\%CI 0.01-0.32; 2-4 years HR 0.37, 95\%CI 0.24-0.57).
\end{abstract}

Conclusions: Younger AAM was not a risk factor for younger age at FSI in this large birth cohort. 


\section{BACKGROUND}

Age at menarche (AAM) marks the onset of reproductive capability and is a commonly utilized milestone for pubertal development. Factors regulating AAM are not well understood, but in developed countries, around half of the variation in AAM is thought to be genetic ${ }^{1,2}$. Other mediating factors include birth and childhood body $\operatorname{size}^{3-6}$, adiposity ${ }^{3,}$, and growth $^{8-10}$, race/ethnicity ${ }^{11-13}$, socioeconomic position ${ }^{13-17}$, family relationships and structure ${ }^{11,16,18,19}$, exposure to childhood adversity and trauma ${ }^{20,21}$. Younger AAM has widely been proposed as a risk factor for early first sexual intercourse (FSI) ${ }^{22,23}$. Exploring the mediators of young age at FSI is of clinical and social significance. Younger age at FSI is associated with sexual risk-taking behaviors including unprotected intercourse ${ }^{24}$, inconsistent contraceptive use ${ }^{25}$, and multiple partners $^{26}$, and with a variety of negative outcomes, including partner violence ${ }^{27}$, lower educational attainment ${ }^{28,29}$, unintended pregnancy ${ }^{30}$, adolescent pregnancy or birth $^{31,32}$, and sexually transmitted infection ${ }^{33-35}$. If girls with younger AAM are at risk of younger age at FSI, they may be a target for educational or other preventive interventions. Current life history theories are based on the assumption that early adversity leads to younger reproduction via younger reproductive capacity and drive $\mathrm{e}^{36,37}$, so the time elapsed between menarche and FSI (gynecologic age at FSI) is also of interest.

Most of the data supporting the association between a younger AAM and earlier onset of sexual activity are cross-sectional ${ }^{16,23,38-45}$. Even the rare prospective cohort studies of this topic have ascertained ages of menarche or sexual intercourse retrospectively ${ }^{46,47}$, have reported only baseline data ${ }^{35}$, or have used analytic methods which represent the probability of FSI at a particular age (e.g. logistic regression) rather than the time to FSI (e.g. hazard models) ${ }^{46,48}$, losing the longitudinal or temporal aspect of the study design. Prospective longitudinal designs have several advantages including the increased accuracy of reporting of timing since the date 
are captured close to the time of the event ${ }^{49,50}$, and the use of use of statistical approaches, such as survival and hazard models, that measure changes within each subject over time, in addition to the difference between groups ${ }^{51}$. Hazard models do not require selecting a cut-off age (e.g. "early" or "normal" age at FSI).

This is the first study to use a large prospective birth cohort to examine closely the temporal relationship between contemporaneously measured AAM and age at FSI. We also report the duration between AAM and FSI to determine whether younger AAM puts girls at risk of a shorter interval to FSI.

\section{METHODS}

\section{PARTICIPANTS}

The Western Australian Pregnancy Cohort (Raine) Study is a prospective cohort study of 2,868 live births (1,405 female, 1,463 male) from 2,900 pregnancies followed since 1989. Complete details of the cohort and initial recruitment procedures are published elsewhere ${ }^{52}$. In brief, the cohort was recruited from a tertiary maternity hospital in Western Australia and followed up at 18 and 34 weeks' gestation with clinical examinations and questionnaire data collection. Children and their families were then followed up at the ages of one, two, three, five, eight, ten, 14, 17, and 20 years with extensive clinical and questionnaire data collected. After the baseline data collection, families were not required to have participated in the previous wave to participate subsequently. Of the birth cohort, 624 girls (44.4\%) participated in the 17-year follow-up and 607 provided valid sexual activity data.

Informed consent was obtained at the time of enrolment in the study and at each follow-up. Study protocols were approved by the Human Ethics Committees at King Edward Memorial Hospital and Princess Margaret Hospital for Children in Perth, Western Australia. 


\section{DATE OF MENARCHE}

Families of girls participating in the 10-year follow-up were given a diary asking the date of menarche and the next two menstrual periods to be returned by mail (prospective ascertainment). If the menstrual diary had not been returned by the 14-year follow-up, mothers and girls received a telephone reminder. If the girl had already experienced menarche at that time, information was collected on the date of menarche including the source of information (e.g. diary, calendar, memory of a coinciding event such as a party or school holiday). Where recall included only the month and year, the day was coded as the fifteenth of the month. For analyses, AAM was classified into younger ( $<12$ years old), average (12-13 years old) and older ( $\geq 14$ years old).

\section{FIRST SEXUAL INTERCOURSE DATA}

Self-reported data on age at first (vaginal) sexual intercourse (FSI) were collected at age 17 years using a confidential questionnaire derived from the National Survey of Secondary School Students, HIV/AIDS and Sexual Health, $2002{ }^{53}$. At the 17-year-follow-up, 607 girls (43.2\% of the original cohort) provided information regarding sexual activity. For those that were not yet sexually active by age 17 , FSI data were obtained at age 20 years.

The interval between AAM and a reproductive endpoint, also referred to as gynecologic age ${ }^{54}$, can provide further insight regarding temporal relationships with respect to reproductive maturity. We calculated the interval between AAM and age at FSI for each girl, and considered the effect of AAM on that interval.

\section{COVARIATES}

Ethnicity $^{14,22,42,55}$, socioeconomic status ${ }^{15,44,56}$, family structure ${ }^{11,55,57}$, and birth size ${ }^{3,11,15}$ ${ }^{58}$ are thought to be associated with both AAM and age at FSI but are unlikely to mediate the relationship. Key variables reflecting these constructs were selected from the data collected at 
baseline and at age 10 to construct an a priori adjusted model. As maternal age at pregnancy was expected to correlate closely with education of both parents, and education reflects socioeconomic advantage, maternal education was prioritized for the adjusted model. The model included maternal ethnicity, education and family income at baseline, expected birth weight ratio (observed birth weight over median birth weight appropriate for maternal height, sex, nulliparity, and gestational age) and absence of biological father at 10 years.

\section{STATISTICAL ANALYSIS}

Continuous data were summarized by means and standard deviations (SD) or medians, interquartile ranges (IQR) and minimum and maximum values, and categorical data were summarized by frequency distributions. We examined the effects of younger, average, and older AAM (see above) on calendar age at FSI and duration between menarche and FSI. Univariate comparisons between groups were conducted using one-way ANOVA or Kruskall-Wallis tests for continuous outcomes and chi-square tests for categorical outcomes. Kaplan-Meier survival probabilities were used to estimate the cumulative incidence of calendar and gynecologic age at FSI.

Survival analysis (event history analysis) methods allow examination of the full range of timing for FSI which does not require a specific cut-off age for early, average or late age at FSI as is required for logistic regression methods. For some survival methods, the assumption of proportional hazards is required - namely, that the absolute risk (hazard) for each group of the predictor of interest (in this case, earlier, average, and later AAM) changes at the same rate across study time, yielding summary relative risks (hazard rate ratios, HR) that are constant across time in comparing the predictor group to the reference group. The proportionate hazard assumption was assessed by inspection of plotted Kaplan-Meier survivor probabilities and, 
where graphical findings were ambiguous, examination of Schoenfeld residuals ${ }^{59}$. Where the Kaplan-Meier curves are parallel for all predictor groups, the proportional hazard assumption is upheld. Where the assumption was violated, extended Cox regression models were used to investigate the time-dependent effects of AAM - separate relative risk estimates were generated for those time intervals over which the risk estimate could be shown to be constant. The effects of AAM were summarized using HR and $95 \%$ confidence intervals (CI). All hypothesis tests were two-sided and p-values $<0.05$ were considered statistically significant. SPSS version 18 (SPSS, IBM Corp., Chicago, IL) software was used for data analysis.

\section{RESULTS}

AGE AT MENARCHE

Of 607 girls participating in the 17-year follow-up, $384(63.3 \%)$ returned the menstrual diary indicating the date of their first three menstrual periods, while 145 (23.9\%) retrospectively reported date of menarche to the closest day or month and $25(4.1 \%)$ to the closest year, totaling 554 complete AAM records. The median AAM was 12.8 years (interquartile range 12.1-13.5 years, range 9.0-16.1 years). The distribution of AAM differed by ethnicity (Table 1).

AGE AT FIRST SEXUAL INTERCOURSE

At the age 17 follow-up, 275 girls $(50.4 \%)$ had initiated sexual intercourse. Of the remaining 279 girls, $233(83.5 \%)$ participated in the 20-year follow-up, of whom $154(66.1 \%)$ had initiated intercourse. Thus, a total of 429 girls had engaged in FSI by the age 20 follow-up (77.4\%).

The median age of FSI for the cohort was 16.0 years (95\% CI 15.8-16.2 y) while the median ages at FSI among girls with younger, average, and older AAM were, respectively, 16 years (IQR 15-20 y, range 13-21 y), 17 years (IQR 15-18 y, range 13-20 y), and 17 years (IQR 16-18 $\mathrm{y}$, range 14-19 y). The cumulative incidence of FSI by age (Table 2) is the proportion of the 
group who have experienced FSI by the end of each year of age. Among girls with younger and average AAM, around a quarter had FSI by age 15, but none of the girls in the older AAM group had FSI before age 14, and only 1 in 10 had FSI by age 15 .

As is illustrated in Figure 1, the slope of incident FSI (absolute FSI risk) was not the same for the three groups across all ages (i.e. the curves cross, indicating that the absolute risk changed at different rates for the three groups, a violation of the proportionate hazards assumption underlying calculation of relative risks in standard Cox regression modeling). On closer examination, within three time intervals, the incidence curves were parallel. Consequently we estimated the relative risks of FSI over those intervals of age for which hazards were proportionate: 15 years of age and under, age 16 years, and 17 years and over (Table 4). Girls with younger AAM and girls with average AAM were equally likely to have FSI by age 15 (adjusted hazard ratio (aHR): 0.90, 95\% confidence interval (CI): 0.60-1.35), and girls with older AAM were only a third as likely as girls with average AAM to experience FSI by age 15 (aHR $0.35,95 \%$ CI $0.17-0.72$ ). All three groups were equally likely to experience FSI at age 16 (younger AAM aHR 1.35, 95\% CI 0.91-2.00; older AAM aHR 1.18, 95\% CI 0.74-1.87). Girls with younger AAM were only half as likely to experience FSI between age 17 and the end of follow-up as girls with average AAM (aHR 0.50, 95\% CI 0.30-0.82), and girls with older AAM and girls with average AAM were equally likely to have FSI between age 17 and the end of follow-up (aHR $0.97,95 \%$ CI 0.63-1.49). Of the potential confounders, only maternal education and father's absence at age 10 significantly affected the likelihood of FSI by calendar age in univariate or multivariate models (maternal tertiary v. high school education: HR $0.58,95 \% \mathrm{CI}$ 0.41-0.83, aHR 0.59, 95\% CI 0.42-0.84; absent father: HR 1.44, 95\% CI 1.17-1.78, aHR 1.40, 95\% CI 1.13-1.72). Adjustment for potential confounders did not substantially change risk 
estimates (Table 4).

INTERVAL BETWEEN MENARCHE AND FIRST SEXUAL INTERCOURSE

No girls had FSI before menarche. The mean interval between menarche and FSI was 3.7 years for girls with average AAM (IQR 2.4-5.3 y, range 0.5-9.0 y), 5.0 years for girls with younger AAM (IQR 4.4-8.5 y, range 1.2-10.8 y), and 2.5 years for girls with older AAM (IQR 1.4-3.9, range 0.0-5.7 y). Cumulative incidence of FSI for each year since menarche for the three groups of AAM are shown in Table 3. Only one girl with younger AAM experienced FSI within two years of menarche, in contrast with the $17 \%$ of girls with average AAM and over $40 \%$ of girls with older AAM.

As with FSI by calendar age, the rate curves for FSI were not parallel across the three AAM groups for the years since menarche (Figure 2). Examination of Schoenfeld residuals confirmed this more subtle departure from proportionality $(\mathrm{p}<0.001)$ so relative rates of FSI were estimated over those intervals for which hazards were proportionate: $<2$ years since menarche, 2-4 years since menarche, and $>4$ years since menarche (Table 4). For the first two years after menarche, girls with younger AAM were much less likely, and girls with older AAM much more likely, to commence sexual activity compared to girls with average AAM (younger aHR 0.04, 95\% CI 0.01-0.31; older AAM aHR 3.46, 95\% CI 2.25-5.31). For the subsequent two years, girls with younger AAM were still less likely to experience FSI than girls with average AAM (aHR 0.36, 95\% CI 0.23-0.55), but girls with older AAM no longer differed (aHR 1.38, 95\% CI 0.87-2.17). Of the potential confounders, as with calendar age, only maternal education and father's absence at age 10 significantly affected the likelihood of FSI by time since menarche (maternal tertiary v. high school education HR 0.52, 95\% CI 0.37-0.74, aHR 0.54, 95\% CI 0.38-0.77; absent father HR 1.40, 95\% CI 1.14-1.72, aHR 1.33, 95\% CI 1.07-1.64). Adjustment for potential 
confounders did not substantially change risk estimates (Table 4).

\section{DISCUSSION}

This is the first prospective study to document the relationship between AAM and both age at FSI and the interval between menarche and FSI. The most striking observation was that younger AAM did not predict younger age at FSI. In addition, within four years of menarche, girls with younger AAM were less likely than girls with average or older AAM to initiate sexual intercourse. Taken together, these data suggest that in this population, younger than average AAM does not confer an increased risk of earlier FSI or of shortened interval between menarche and FSI. This was true even when accounting for early life growth, socioeconomic variables and father absence at puberty. This may have implications for the life history theories which presuppose that adversity leads to earlier puberty (including menarche) and then earlier reproduction $^{36,60}$. In clinical practice, younger AAM alone does not appear to put girls at risk of younger age at FSI and teenage pregnancy. Other factors such as psychosocial and cognitive development may provide better targets for interventions. The median AAM in our study (12.8 years) was similar to that reported in other recent population based studies in Australia (12.9y, $\mathrm{N}=9683^{27}$; Penrith birth cohort $\left.12.6 \mathrm{y}, \mathrm{N}=156^{61}\right)$, the UK (12.9 y, $\left.\mathrm{N}=3938^{62}\right)$, Canada (12.7 y, $\mathrm{N}=1403^{63}$, and the United States $\left(12 \mathrm{y}, \mathrm{N}=262^{64}\right)$. The cohort median age of FSI (16 y) is comparable to a representative sample of Australians ${ }^{65}$, and to current measures in the $\mathrm{UK}^{66}$, but older than that in the US (15.0-15.3 y ${ }^{67}$. Nearly a quarter of participants had still not initiated sexual intercourse by age 20 or 21 . It is unlikely that age of FSI was reported erroneously, as these data were collected using a standardized written instrument that has previously been used successfully ${ }^{53}$.

Compared with previous longitudinal studies, our study has a number of strengths. Ours is the 
first study to use hazard modeling, which permits calculation of FSI risk by AAM category in empirically derived age groups rather than at a specific cut-off age, and which accounts for loss to follow-up prior to the occurrence of the event of interest (addressing "right censoring"). Another difference is that studies categorizing AAM dichotomously may distort the relationship between AAM and age at FSI. The older a girl is at menarche, the lower her risk of commencing sexual intercourse at younger ages. Comparing a group of earlier-maturing girls to a reference group that includes later-maturing girls (who delay FSI relative to the average) would overstate the likelihood of FSI for the earlier-maturing girls. More accurate categorization of AAM separates girls into groups with younger, average, and older ages at menarche.

Both the Christchurch Health and Development Study (CHDS cohort) ${ }^{48}(\mathrm{~N}=497)$ the Dunedin cohort study 44, 46, 69 ( $\mathrm{N}=477$ ) found an association between AAM (continuously measured in months, or appropriately categorized) and earlier age at FSI. Our novel analytic approach may account for some of this disparity. Cohort effects are possible but unlikely (the Raine cohort was born 12 years after the CHDS and 17 after the Dunedin cohort). The Great Smoky Mountains longitudinal study $(\mathrm{N}=630)$ found that early-maturing girls were more likely to engage in sexual intercourse before age $16^{70}$; however, they used a composite measure of pubertal timing including AAM and Tanner staging. The discrepancy between our finding and theirs is most likely accounted for partly by the difference in maturity markers and partly by their decision to include both "on-time" and late-maturing girls in the comparison group.

Only one other study has examined the relationship between AAM and the interval between menarche and FSI. Segal and Stohs ${ }^{71}$ report that, amongst 44 twin pairs, AAM was inversely related to interval between menarche and FSI, consistent with our findings. 


\section{CONCLUSIONS}

This is the first large birth cohort study to prospectively report the relationship between AAM and first sexual intercourse using longitudinal analyses. Younger age at reproductive maturity (AAM) did not predict younger age at FSI. Further, we have shown that the interval between AAM and FSI is longer for girls with a younger AAM than those with an average or older AAM. These findings are of social and clinical significance. However, menarche is a relatively late

event in pubertal progression ${ }^{72}$. Recent international data strongly suggest earlier onset and faster tempo of puberty in some populations, without an overall population reduction in the $\mathrm{AAM}^{73-75}$. Greater understanding of factors regulating the onset and tempo of puberty are likely to further inform how sexual behavior, reproductive and emotional development are interlinked. 


\section{Acknowledgements}

We acknowledge the funding and support of the Raine Medical Research Foundation, The University of Western Australia (UWA), the National Health and Medical Research Council of Australia (NHMRC), the Telethon Institute for Child Health Research, the Telstra Foundation, the Western Australian Health Promotion Foundation, the UWA Faculty of Medicine, Dentistry and Health Science, the Women and Infants Research Foundation, and Australian Health Management. Dr Robinson is funded by Australian Rotary Health. We are extremely grateful to all the families who took part in this study and the Raine Study team, which includes data collectors, cohort managers, data managers, clerical staff, research scientists and volunteers.

\section{References}

1. Towne B, Czerwinski SA, Dernerath EW, Blangero J, Roche AF, Siervogel RM. Heritability of age at menarche in girls from the Fels Longitudinal Study. Am J Phys Anthropol. 2005;128(1):210-219.

2. Morris DH, Jones ME, Schoemaker MJ, Ashworth A, Swerdlow AJ. Familial concordance for age at menarche: analyses from the Breakthrough Generations Study. Paediatr Perinat Ep. 2011;25(3):306-311.

3. Sloboda DM, Hickey M. Developmental Origins of Reproductive Health. In: Newnham JP, Ross MG, editors. Early Life Origins of Human Health and Disease. Basel, Switzerland: Karger; 2009. p. 113-122.

4. Rosenfield RL, Lipton RB, Drum ML. Thelarche, pubarche, and menarche attainment in children with normal and elevated body mass index. Pediatrics. 2009;123(1):84-88.

5. Blell M, Pollard TM, Pearce MS. Predictors of age at menarche in the newcastle thousand families study. J Biosoc Sci. 2008;40(4):563-575.

6. Bosch AM, Willekens FJ, Baqui AH, Van Ginneken JK, Hutter I. Association between age at menarche and early-life nutritional status in rural Bangladesh. J Biosoc Sci. 2008;40(2):223-237.

7. Wagner IV, Sabin MA, Pfaffle RW, Hiemisch A, Sergeyev E, Korner A, et al. Effects of obesity on human sexual development. Nat Rev Endocrinol. 2012;8(4):246-254.

8. Rubin C, Maisonet M, Kieszak S, Monteilh C, Holmes A, Flanders D, et al. Timing of maturation and predictors of menarche in girls enrolled in a contemporary British cohort. Paediatr Perinat Epidemiol. 2009;23(5):492-504.

9. dos Santos Silva I, De Stavola BL, Mann V, Kuh D, Hardy R, Wadsworth ME. Prenatal factors, childhood growth trajectories and age at menarche. Int J Epidemiol. 2002;31(2):405-412.

10. Cooper C, Kuh D, Egger P, Wadsworth M, Barker D. Childhood growth and age at menarche. $\mathrm{Br}$ J Obstet Gynaecol. 1996;103(8):814-817.

11. Morris DH, Jones ME, Schoemaker MJ, Ashworth A, Swerdlow AJ. Determinants of age at menarche in the UK: analyses from the Breakthrough Generations Study. $B r J$ Cancer. 2010;103(11):1760-1764.

12. Freedman DS, Khan LK, Serdula MK, Dietz WH, Srinivasan SR, Berenson GS. Relation of age at menarche to race, time period, and anthropometric dimensions: the Bogalusa Heart Study. Pediatrics. 2002;110(4):e43.

13. Obeidallah DA, Brennan RT, Brooks-Gunn J, Kindlon D, Earls F. Socioeconomic status, race, and girls' pubertal maturation: Results from the project on human development in Chicago neighborhoods. J Res Adolescence. 2000;10(4):443-464.

14. Braithwaite D, Moore DH, Lustig RH, Epel ES, Ong KK, Rehkopf DH, et al. Socioeconomic status in relation to early menarche among black and white girls. Cancer Causes Control. 2009;20(5):713-720.

15. Dossus L, Kvaskoff M, Bijon A, Fervers B, Boutron-Ruault MC, Mesrine S, et al. Determinants of age at menarche and time to menstrual cycle regularity in the French E3N cohort. Ann Epidemiol. 2012;22(10):723-730. 
16. Deardorff J, Gonzales NA, Christopher FS, Roosa MW, Millsap RE. Early puberty and adolescent pregnancy: the influence of alcohol use. Pediatrics. 2005;116(6):1451-1456.

17. Arim RG, Tramonte L, Shapka JD, Dahinten VS, Willms JD. The family antecedents and the subsequent outcomes of early puberty. J Youth Adolesc. 2011;40(11):1423-1435.

18. Milne FH, Judge DS. Brothers delay menarche and the onset of sexual activity in their sisters. Proc Biol Sci. 2011;278(1704):417-423.

19. Bogaert AF. Menarche and father absence in a national probability sample. $J$ Biosoc Sci. 2008;40(4):623-636.

20. Boynton-Jarrett R, Harville EW. A prospective study of childhood social hardships and age at menarche. Annals of Epidemiology. 2012;22(10):731-737.

21. Pesonen AK, Raikkonen K, Heinonen K, Kajantie E, Forsen T, Eriksson JG. Reproductive traits following a parent-child separation trauma during childhood: A natural experiment during World War II. American Journal of Human Biology. 2008;20(3):345-351.

22. Udry JR. Age at menarche, at first intercourse, and at first pregnancy. $J$ Biosoc Sci. 1979;11(4):433-441.

23. Helm P, Lidegaard O. The relationship between menarche and sexual, contraceptive, and reproductive life events. Scandinavian Journal of Primary Health Care. 1990;8(1):59-63.

24. Cavazos-Rehg PA, Krauss MJ, Spitznagel EL, Schootman M, Peipert JF, Cottler LB, et al. Type of contraception method used at last intercourse and associations with health risk behaviors among US adolescents. Contraception. 2010;82(6):549-555.

25. Magnusson BM, Masho SW, Lapane KL. Early age at first intercourse and subsequent gaps in contraceptive use. J Womens Health (Larchmt). 2012;21(1):73-79.

26. Langille DB, Asbridge M, Flowerdew G, Allen M. Associations of sexual risk-taking with having intercourse before 15 years in adolescent females in Cape Breton, Nova Scotia, Canada. Sex Health. 2010;7(2):199-204.

27. Watson LF, Taft AJ, Lee C. Associations of self-reported violence with age at menarche, first intercourse, and first birth among a national population sample of young Australian women. Womens Health Issues. 2007;17(5):281-289.

28. Steward NR, Farkas G, Bingenheimer JB. Detailed educational pathways among females after very early sexual intercourse. Perspect Sex Reprod Health. 2009;41(4):244-252.

29. Spriggs AL, Halpern CT. Timing of sexual debut and initiation of postsecondary education by early adulthood. Perspect Sex Reprod Health. 2008;40(3):152-161.

30. Magnusson BM, Masho SW, Lapane KL. Adolescent and sexual history factors influencing reproductive control among women aged 18-44. Sex Health. 2011;8(1):95-101.

31. van Roode T, Dickson N, Sharples K, Paul C. Patterns of sexual partnering and reproductive history: associations with timing of first birth in a birth cohort. Perspect Sex Reprod Health. 2012;44(1):48-56.

32. Buston K, Williamson L, Hart G. Young women under 16 years with experience of sexual intercourse: who becomes pregnant? J Epidemiol Community Health. 2007;61(3):221-225.

33. Kaestle CE, Halpern CT, Miller WC, Ford CA. Young age at first sexual intercourse and sexually transmitted infections in adolescents and young adults. Am J Epidemiol. 2005;161(8):774-780.

34. Coker AL, Richter DL, Valois RF, McKeown RE, Garrison CZ, Vincent ML. Correlates and consequences of early initiation of sexual intercourse. J Sch Health. 1994;64(9):372-377.

35. Andersson-Ellstrom A, Forssman L, Milsom I. Age of sexual debut related to life-style and reproductive health factors in a group of Swedish teenage girls. Acta obstetricia et gynecologica Scandinavica. 1996;75(5):484-489.

36. Belsky J. The Development of Human Reproductive Strategies: Progress and Prospects. Curr Dir Psychol Sci. 2012;21(5):310-316.

37. Belsky J, Steinberg L, Draper P. Childhood experience, interpersonal development, and reproductive strategy: and evolutionary theory of socialization. Child Dev. 1991;62(4):647-670.

38. Lam TH, Shi HJ, Ho LM, Stewart SM, Fan S. Timing of pubertal maturation and heterosexual 
behavior among Hong Kong Chinese adolescents. Arch Sex Behav. 2002;31(4):359-366.

39. Gaudineau A, Ehlinger V, Vayssiere C, Jouret B, Arnaud C, Godeau E. Factors associated with early menarche: results from the French Health Behaviour in School-aged Children (HBSC) study. BMC public health. 2010;10:175.

40. Magnusson C. Adolescent girls' sexual attitudes and opposite-sex relations in 1970 and in 1996. $J$ Adolesc Health. 2001;28(3):242-252.

41. Edgardh K. Sexual behaviour and early coitarche in a national sample of 17 year old Swedish girls. Sex Transm Infect. 2000;76(2):98-102.

42. Phinney VG, Jensen LC, Olsen JA, Cundick B. The relationship between early development and psychosexual behaviors in adolescent females. Adolescence. 1990;25(98):321-332.

43. Wyatt G, Durvasula RS, Guthrie D, LeFranc E, Forge N. Correlates of first intercourse among women in Jamaica. Arch Sex Behav. 1999;28(2):139-157.

44. Rosenthal SL, Von Ranson KM, Cotton S, Biro FM, Mills L, Succop PA. Sexual initiation Predictors and developmental trends. Sexually Transmitted Diseases. 2001;28(9):527-532.

45. Udry JR, Cliquet RL. A Cross-Cultural Examination of the Relationship between Ages at Menarche, Marriage, and 1st Birth. Demography. 1982;19(1):53-63.

46. Paul C, Fitzjohn J, Herbison P, Dickson N. The determinants of sexual intercourse before age 16. J Adolesc Health. 2000;27(2):136-147.

47. Miller BC, Norton MC, Curtis T, Hill EJ, Schvaneveldt P, Young MH. The timing of sexual intercourse among adolescents - Family, peer and other antecedents. Youth Soc. 1997;29(1):5483.

48. Boden JM, Fergusson DM, Horwood LJ. Age of menarche and psychosocial outcomes in a New Zealand birth cohort. J Am Acad Child Adolesc Psychiatry. 2011;50(2):132-140 e135.

49. Cairns BJ, Liu B, Clennell S, Cooper R, Reeves GK, Beral V, et al. Lifetime body size and reproductive factors: comparisons of data recorded prospectively with self reports in middle age. BMC Med Res Methodol. 2011;11:7.

50. Cooper R, Blell M, Hardy R, Black S, Pollard TM, Wadsworth ME, et al. Validity of age at menarche self-reported in adulthood. J Epidemiol Community Health. 2006;60(11):993-997.

51. Diggle P. Analysis of longitudinal data. 2nd ed. Oxford ; New York: Oxford University Press; 2002.

52. Newnham JP, Evans SF, Michael CA, Stanley FJ, Landau LI. Effects of frequent ultrasound during pregnancy: a randomised controlled trial. Lancet. 1993;342(8876):887-891.

53. Smith A, Agius P, Mitchell A, Barrett C, Pitts M. Secondary Students and Sexual Health 2008. Melbourne: Australian Research Centre in Sex, Health \& Society, La Trobe University.; 2009.

54. Zlatnik FJ, Burmeister LF. Low 'gynecologic age': an obstetric risk factor. Am J Obstet Gynecol. 1977;128(2):183-186.

55. Zimmer-Gembeck MJ, Helfand M. Ten years of longitudinal research on US adolescent sexual behavior: Developmental correlates of sexual intercourse, and the importance of age, gender and ethnic background. Dev Rev. 2008;28(2):153-224.

56. Bingham CR, Miller BC, Adams GR. Correlates of age at first sexual intercourse in a national sample of young women. J Adolesc Res. 1990;5(1):18-33.

57. Mendle J, Harden KP, Turkheimer E, Van Hulle CA, D'Onofrio BM, Brooks-Gunn J, et al. Associations between father absence and age of first sexual intercourse. Child Dev. 2009;80(5):1463-1480.

58. Nettle D, Coall DA, Dickins TE. Early-life conditions and age at first pregnancy in British women. Proc Biol Sci. 2011;278(1712):1721-1727.

59. Therneau TM, Grambsch PM. Modeling survival data: extending the Cox model: Springer; 2000.

60. Mishra GD, Cooper R, Tom SE, Kuh D. Early life circumstances and their impact on menarche and menopause. Womens Health (Lond Engl). 2009;5(2):175-190.

61. Tam CS, de Zegher F, Garnett SP, Baur LA, Cowell CT. Opposing influences of prenatal and postnatal growth on the timing of menarche. J Clin Endocrinol Metab. 2006;91(11):4369-4373. 
62. Christensen KY, Maisonet M, Rubin C, Holmes A, Flanders WD, Heron J, et al. Progression through puberty in girls enrolled in a contemporary British cohort. J Adolesc Health. 2010;47(3):282-289.

63. Al-Sahab B, Ardern CI, Hamadeh MJ, Tamim H. Age at menarche in Canada: results from the National Longitudinal Survey of Children \& Youth. BMC public health. 2010;10:736.

64. Terry MB, Ferris JS, Tehranifar P, Wei Y, Flom JD. Birth weight, postnatal growth, and age at menarche. Am J Epidemiol. 2009;170(1):72-79.

65. Rissel CE, Richters J, Grulich AE, de Visser RO, Smith AM. Sex in Australia: first experiences of vaginal intercourse and oral sex among a representative sample of adults. Aust $N$ Z J Public Health. 2003;27(2):131-137.

66. Hawes ZC, Wellings K, Stephenson J. First heterosexual intercourse in the United kingdom: a review of the literature. J Sex Res. 2010;47(2):137-152.

67. Manlove J, Ikramullah E, Mincieli L, Holcombe E, Danish S. Trends in sexual experience, contraceptive use, and teenage childbearing: 1992-2002. J Adolesc Health. 2009;44(5):413-423.

68. Cavazos-Rehg PA, Spitznagel EL, Bucholz KK, Nurnberger J, Jr., Edenberg HJ, Kramer JR, et al. Predictors of sexual debut at age 16 or younger. Arch Sex Behav. 2010;39(3):664-673.

69. Moffitt TE, Caspi A, Belsky J, Silva PA. Childhood experience and the onset of menarche: a test of a sociobiological model. Child Dev. 1992;63(1):47-58.

70. Copeland W, Shanahan L, Miller S, Costello EJ, Angold A, Maughan B. Outcomes of early pubertal timing in young women: a prospective population-based study. Am J Psychiatry. 2010;167(10):1218-1225.

71. Segal NL, Stohs JH. Age at first intercourse in twins reared apart: Genetic influence and life history events. Pers Indiv Differ. 2009;47(2):127-132.

72. Dorn LD, Biro FM. Puberty and Its Measurement: A Decade in Review. J Res Adolescence. 2011;21(1):180-195.

73. Parent AS, Teilmann G, Juul A, Skakkebaek NE, Toppari J, Bourguignon JP. The timing of normal puberty and the age limits of sexual precocity: variations around the world, secular trends, and changes after migration. Endocr Rev. 2003;24(5):668-693.

74. Walvoord EC. The Timing of Puberty: Is It Changing? Does It Matter? J Adolescent Health. 2010;47(5):433-439.

75. Ong KK, Ahmed ML, Dunger DB. Lessons from large population studies on timing and tempo of puberty (secular trends and relation to body size): the European trend. Mol Cell Endocrinol. 2006;254-255:8-12. 
Table 1. Demographic profile of study participants stratified by age at menarche (AAM). Percentages within each group may not add to $100 \%$ due to missing data.

\begin{tabular}{|c|c|c|c|c|c|}
\hline Characteristic & $\begin{array}{c}\text { Average } \\
\text { AAM (12-13y) } \\
\mathrm{N}=353(\%)\end{array}$ & $\begin{array}{c}\text { Younger AAM } \\
(<\mathbf{1 2 y}) \\
\mathrm{N}=123(\%)\end{array}$ & $\begin{array}{c}\text { Older AAM } \\
(\geq \mathbf{1 4 y}) \\
\mathrm{N}=78(\%) \\
\end{array}$ & $\begin{array}{c}\text { Total } \\
\mathrm{N}=554(\%)\end{array}$ & $p$ \\
\hline \multicolumn{6}{|l|}{$\begin{array}{l}\text { Maternal } \\
\text { ethnicity }\end{array}$} \\
\hline $\begin{array}{l}\text { Caucasian } \\
\text { Non- }\end{array}$ & $316(89.5)$ & $100(81.3)$ & $71(91.0)$ & 487 (87.9) & 0.01 \\
\hline Caucasian* & $29(8.2)$ & $21(17.7)$ & $5(6.4)$ & $55(9.9)$ & \\
\hline \multicolumn{6}{|l|}{$\begin{array}{l}\text { Maternal age at } \\
\text { birth }\end{array}$} \\
\hline$<25$ years & 94 (26.6) & 38 (30.9) & $24(30.8)$ & $156(28.2)$ & 0.87 \\
\hline $25-35$ years & $206(58.4)$ & $69(56.1)$ & $43(55.1)$ & $318(57.4)$ & \\
\hline$>35$ years & $53(15.0)$ & $16(13.0)$ & $11(14.1)$ & $80(14.4)$ & \\
\hline \multicolumn{6}{|l|}{$\begin{array}{l}\text { Family income } \\
\text { at pregnancy }\end{array}$} \\
\hline$<\$ 12,000$ & $58(16.4)$ & $21(17.1)$ & $17(21.8)$ & $96(17.3)$ & 0.555 \\
\hline$\$ 12000-\$ 35,999$ & $158(44.7)$ & $61(49.6)$ & $33(42.3)$ & $252(45.5)$ & \\
\hline$\geq \$ 36,000$ & $116(15.0)$ & $33(26.8)$ & $22(28.2)$ & $171(30.9)$ & \\
\hline \multicolumn{6}{|l|}{$\begin{array}{l}\text { Maternal } \\
\text { education }\end{array}$} \\
\hline $\begin{array}{l}<\text { High school } \\
\text { High school }\end{array}$ & $\begin{array}{c}85(24.1) \\
60(17.0) \\
133(\end{array}$ & $\begin{array}{l}37(30.0) \\
15(12.2)\end{array}$ & $\begin{array}{l}14(17.9) \\
14(17.9)\end{array}$ & $\begin{array}{l}151(27.3) \\
99(17.9)\end{array}$ & 0.44 \\
\hline Trade & $37.7)$ & $51(41.5)$ & 34 (43.6) & 236 (41.6) & \\
\hline Tertiary & $52(14.7)$ & $14(11.4)$ & $11(14.1)$ & $80(14.4)$ & \\
\hline EBW & & & & & \\
\hline $\begin{array}{l}\text { Mean }(\mathrm{SD}) \\
\text { Father absence } \\
\text { at 10-year } \\
\text { follow-up }\end{array}$ & $1.01(0.13)$ & $1.01(0.12)$ & $1.01(0.17)$ & $1.01(0.13)$ & 0.850 \\
\hline $\begin{array}{l}\text { Not living with } \\
\text { family }\end{array}$ & $103(30.3)$ & 37 (30.6) & $20(26.0)$ & $160(29.7)$ & 0.736 \\
\hline
\end{tabular}

*Aboriginal: 5 (0.9\%); Polynesian 5 (0.9\%); Vietnamese 1 (0.2\%); Chinese 22 (4.0\%); Indian 14 $(2.5 \%)$; Other $8(1.4 \%)$; SES = social economic status; Income at pregnancy was recorded during 1989-1992 \$AUD. EBW = expected birth weight ratio reflecting birth size for gestational age. 
Table 2. Estimated cumulative incidence of sexual intercourse for each year of age, by age at menarche (AAM)

\begin{tabular}{|c|c|c|c|c|c|c|c|c|c|}
\hline \multirow{3}{*}{$\begin{array}{l}\mathrm{N}=554 \\
\text { Age }\end{array}$} & \multicolumn{3}{|c|}{ Average AAM (12-13y) } & \multicolumn{3}{|c|}{ Earlier AAM $(<12 y)$} & \multicolumn{3}{|c|}{ Later AAM ( $\geq 14 y)$} \\
\hline & $\mathrm{N}$. & N. & & $\mathrm{N}$. & N. & & N. & N. & \\
\hline & Risk & SI & $\%(95 \% \mathrm{CI})$ & Risk & SI & $\%(95 \% \mathrm{CI})$ & Risk & SI & $\%(95 \% \mathrm{CI})$ \\
\hline 13 & 353 & 5 & $1.4(0.2-2.6)$ & 123 & 3 & $2.4(0.0-5.2)$ & 79 & 0 & - \\
\hline 14 & 348 & 31 & $10.2(7.0-13.4)$ & 120 & 14 & $13.8(7.7-19.9)$ & 78 & 1 & $1.3(0.0-3.8)$ \\
\hline 15 & 317 & 65 & $28.6(23.9-33.3)$ & 106 & 14 & $25.2(17.5-32.9)$ & 77 & 7 & $10.3(3.5-17.0)$ \\
\hline 16 & 252 & 75 & $49.9(44.6-55.1)$ & 92 & 38 & $56.1(47.3-64.9)$ & 70 & 24 & $41.0(30.1-51.9)$ \\
\hline 17 & 165 & 48 & $64.4(59.4-69.5)$ & 48 & 5 & $60.7(51.9-69.4)$ & 42 & 11 & $56.5(45.2-67.7)$ \\
\hline 18 & 103 & 34 & $76.2(71.5-80.9)$ & 37 & 9 & $70.2(61.7-78.8)$ & 28 & 12 & $75.1(64.9-85.4)$ \\
\hline 19 & 68 & 24 & $84.6(80.5-88.7)$ & 28 & 2 & $72.4(63.9-80.8)$ & 16 & 3 & $79.8(70.2-89.4)$ \\
\hline 20 & 18 & 1 & $85.4(81.3-89.6)$ & 14 & 2 & $76.3(67.5-85.1)$ & 8 & 0 & - \\
\hline 21 & 2 & 1 & $92.7(82.4-100)$ & 12 & 0 & - & 1 & 0 & - \\
\hline
\end{tabular}

$\mathrm{N}$ risk $=$ number of adolescents that have not previously debuted in sexual intercourse; $\mathrm{N} \mathrm{SI}=$ number of adolescents debuting in sexual intercourse

Table 3. Estimated cumulative incidence of sexual intercourse for each year since menarche, by age at menarche (AAM)

\begin{tabular}{|c|c|c|c|c|c|c|c|c|c|}
\hline \multirow{2}{*}{$\begin{array}{l}\mathrm{N}=554 \\
\text { Years }\end{array}$} & \multicolumn{3}{|c|}{ Average AAM (12-13y) } & \multicolumn{3}{|c|}{ Earlier AAM $(<12 y)$} & \multicolumn{3}{|c|}{ Later AAM ( $\geq 14 y)$} \\
\hline & $\begin{array}{c}\text { N. } \\
\text { Risk }\end{array}$ & $\begin{array}{l}\text { N. } \\
\text { SI }\end{array}$ & $\%(95 \% \mathrm{CI})$ & $\begin{array}{c}\text { N. } \\
\text { Risk }\end{array}$ & $\begin{array}{l}\text { N. } \\
\text { SI }\end{array}$ & $\%(95 \% \mathrm{CI})$ & $\begin{array}{c}\text { N. } \\
\text { Risk }\end{array}$ & $\begin{array}{l}\text { N. } \\
\text { SI }\end{array}$ & $\%(95 \% \mathrm{CI})$ \\
\hline$<1$ & 353 & 10 & $2.8(1.1-4.6)$ & 123 & 0 & - & 78 & 10 & $12.8(5.4-20.2)$ \\
\hline 1 & 343 & 50 & $17.0(13.1-20.9)$ & 123 & 1 & $0.8(0.0-2.4)$ & 67 & 23 & $42.7(31.7-53.8)$ \\
\hline 2 & 293 & 82 & $40.2(35.1-45.3)$ & 122 & 15 & $13.0(7.1-19.0)$ & 41 & 13 & $60.9(49.8-72.0)$ \\
\hline 3 & 203 & 53 & $55.8(50.6-61.1)$ & 107 & 11 & $22.0(14.6-29.3)$ & 25 & 9 & $75.0(64.7-85.2)$ \\
\hline 4 & 139 & 45 & $70.1(65.2-75.1)$ & 96 & 34 & $49.6(40.8-58.4)$ & 14 & 3 & $80.3(70.7-90.0)$ \\
\hline 5 & 87 & 29 & $80.1(75.7-84.5)$ & 58 & 13 & $60.9(52.2-69.6)$ & 6 & 0 & - \\
\hline 6 & 48 & 14 & $85.9(81.8-89.9)$ & 40 & 8 & $68.7(60.2-77.2)$ & & & \\
\hline 7 & 8 & 1 & $87.7(82.9-92.5)$ & 29 & 2 & $70.9(62.4-79.3)$ & & & \\
\hline 8 & 1 & 0 & - & 19 & 2 & $73.9(65.4-82.5)$ & & & \\
\hline 9 & & & & 7 & 1 & $77.7(67.7-87.6)$ & & & \\
\hline 10 & & & & 1 & 0 & - & & & \\
\hline
\end{tabular}

$\mathrm{N}$ risk = number of adolescents that have not previously debuted in sexual intercourse; $\mathrm{N} \mathrm{SI}=$ number of adolescents debuting in sexual intercourse 
Table 4. Relative risk of first sexual intercourse (FSI) for girls with younger and older ages at menarche (AAM) compared to girls with average AAM, for risk-stable intervals of years of age (calendar age) and years since menarche (gynecologic age).

\begin{tabular}{|c|c|c|c|c|c|c|c|c|}
\hline & \multicolumn{4}{|c|}{$\begin{array}{l}\text { Unadjusted relative risk of FSI } \\
\end{array}$} & \multicolumn{4}{|c|}{$\begin{array}{l}\text { Adjusted } * \text { relative risk of FSI } \\
\end{array}$} \\
\hline & $\begin{array}{c}\text { Younger AAM } \\
\text { (<12 years) } \\
\text { HR }(95 \% \text { CI })\end{array}$ & $\mathrm{p}$ & $\begin{array}{c}\text { Older AAM } \\
(\geq 14 \text { years }) \\
\text { HR }(95 \% \mathrm{CI})\end{array}$ & $\mathrm{p}$ & $\begin{array}{c}\text { Younger AAM } \\
\text { (<12 years) } \\
\text { HR }(95 \% \mathrm{CI})\end{array}$ & $\mathrm{p}$ & $\begin{array}{c}\text { Older AAM } \\
(\geq \mathbf{1 4} \text { years }) \\
\text { HR }(95 \% \mathrm{CI})\end{array}$ & $\mathrm{p}$ \\
\hline \multicolumn{9}{|c|}{ Calendar age } \\
\hline$\leq 15$ years & $0.91(0.61-1.36)$ & 0.632 & $0.34(0.16-0.69)$ & 0.003 & $0.90(0.60-1.35)$ & 0.620 & $0.35(0.17-0.72)$ & 0.004 \\
\hline 16 years & $1.39(0.94-2.05)$ & 0.100 & $1.15(0.73-1.82)$ & 0.546 & $1.35(0.91-2.00)$ & 0.136 & $1.18(0.74-1.87)$ & 0.486 \\
\hline$\geq 17$ years & $0.48(0.29-0.79)$ & 0.004 & $0.92(0.60-1.41)$ & 0.707 & $0.50(0.30-0.82)$ & 0.007 & $0.97(0.63-1.49)$ & 0.884 \\
\hline \multicolumn{9}{|c|}{ Time since menarche } \\
\hline$<2$ years & $0.04(0.01-0.32)$ & 0.002 & $3.15(2.06-4.82)$ & $<0.001$ & $0.04(0.01-0.31)$ & 0.002 & $3.46(2.25-5.31)$ & $<0.001$ \\
\hline $2-4$ years & $0.37(0.25-0.57)$ & $<0.001$ & $1.22(0.78-1.92)$ & 0.387 & $0.36(0.23-0.55)$ & $<0.001$ & $1.38(0.87-2.17)$ & 0.168 \\
\hline$>4$ years & $0.82(0.59-1.15)$ & 0.250 & $0.49(0.15-1.55)$ & 0.225 & $0.80(0.57-1.12)$ & 0.191 & $0.56(0.18-1.79)$ & 0.330 \\
\hline
\end{tabular}

Reference group was girls with average AAM.

*Adjusted for maternal ethnicity (Caucasian vs. Other) and education (<high school, high school, trade, tertiary), family income at pregnancy (<\$AUD 12K, \$AUD 12-35K, $\geq$ \$AUD 36K), expected birth weight ratio and absence of biological father at age 10 years. 
Figure legends (see figure file)

Figure 1. Cumulative incidence of first sexual intercourse by years of age among girls with earlier, average, and later ages at menarche.

Figure 2. Cumulative incidence of first sexual intercourse by years since menarche (gynecologic age) among girls with earlier, average, and later ages at menarche. 